УДК $630 * 311: 630 * 307$

МИНИМИЗАЦИЯ ТЕХНОГЕННОГО ВОЗДЕЙСТВИЯ ЛЕСНЫХ МАШИН
НА ЭКОСИСТЕМЫ ЛЕСОВ НА ОСНОВЕ КЛАСТЕРИЗАЦИИ
ПРИРОДНО-ПРОИЗВОДСТВЕННЫХ УСЛОВИЙ ЛЕСОЗАГОТОВОК

${ }^{1}$ Шегельман И.Р., ${ }^{2}$ Будник П.В., ${ }^{3}$ Баклагин В.Н.

${ }^{1}$ Карельская региональная общественная организаџия «Инженерная академия», Петрозаводск, e-mail: shegelman@onego.ru;

${ }^{2}$ ФБОУ ВО «Петрозаводский государственный университет»,

Петрозаводск, е-mail: budnikpavel@yandex.ru;

${ }^{3}$ ФБУН «Институт водных проблем Севера» Карельского научного ичентра РАН, Петрозаводск, е-mail: slava.baklagin@mail.ru

В статье описан подход к повышению экологической безопасности лесозаготовительных работ и обеспечению их экономической эффективности на основе методики аналитической типизации природно-производственных условий (ППУ) лесозаготовок, базирующейся на применении кластерного анализа. Исследования проведены для регионов Европейского Севера России, включая Мурманскую область, Республику Карелия, Архангельскую область, Вологодскую область, Республику Коми. Цель исследований заключалась в выделении зон лесных территорий на Европейском Севере России со схожими ППУ лесозаготовок, а также в разработке для них рекомендаций по применению лесозаготовительных машин, направленных на минимизацию техногенного воздействия на лесную среду в процессе лесозаготовок. Исследования включали следующие этапы: 1) сбор данных, характеризующих ППУ на Европейском Севере России; 2) определение значений индикаторов, характеризующих ППУ; 3 ) формирование наборов из индикаторов, по которым осуществляется сравнение регионов; 4) типизация регионов на основе кластерного анализа. Исследования проведены на данных лесных планов субъектов Российской Федерации, данных Федерального агентства лесного хозяйства Российской Федерации, картографических материалов регионов Европейского Севера России, находящихся в открытом доступе. В результате проведенных исследований установлено, что может быть выделено 5 зон со схожими ППУ. Зоны получили условные обозначения: А, В, В1, В2, С. Зона А включает Мурманскую область. В зону В входят Республика Карелия, Республика Коми и Архангельская область. В зону С входит Вологодская область. Зона В1 выделена в приграничной с Финляндией зоне Республики Карелия. Зона В2 выделена в восточной части Республики Коми. Для каждой зоны определены системы лесозаготовительных машин, позволяющих снизить негативное воздействие на экосистему леса в ходе лесозаготовок.

Ключевые слова: типизация природно-производственных условий, Европейский Север России, системы лесозаготовительных машин

\title{
MINIMIZATION OF TECHNOGENIC EFFECTS OF FOREST MACHINES ON FOREST ECOSYSTEMS BASED ON THE CLUSTERING OF NATURAL-PRODUCTION CONDITIONS FOR FORESTRY
}

${ }^{1}$ Shegelman I.R., ${ }^{2}$ Budnik P.V., ${ }^{3}$ Baklagin V.N.

${ }^{1}$ Karelian regional public organization «Engineering Academy», Petrozavodsk, e-mail: shegelman@onego.ru;

2Petrozavodsk State University (PetrSU),Petrozavodsk, e-mail: budnikpavel@yandex.ru;

${ }^{3}$ Institute of northern water problems Karelian research center of RAS, Petrozavodsk,e-mail: slava.baklagin@mail.ru

\begin{abstract}
The paper describes an approach to improving the environmental safety of logging operations and ensuring their economic efficiency on the basis of the method of analytical typification of natural-production logging conditions (NPL), based on the use of cluster analysis. Studies have been conducted for the regions of the European North of Russia, including the Murmansk region, the Republic of Karelia, the Arkhangelsk region, the Vologda region, and the Republic of Komi. The purpose of the research was to identify zones of forest areas in the European North of Russia with similar NPL, as well as to develop recommendations on the use of logging machines for zones aimed at minimizing the technogenic impact on the forest environment during forest harvesting. The studies included the following stages: 1) collection of data characterizing NPL of the regions of the European North of Russia; 2) determination of the values of indicators characterizing NPL; 3) the formation of sets of indicators, by which regions are compared; 4) the typification of regions based on cluster analysis. The studies were carried out on the data of forest plans of the subjects of the Russian Federation, data of the Federal Forestry Agency of the Russian Federation, cartographic materials of the regions of the European North of Russia, which are publicly available. As a result of the conducted researches it is established that in the European North of Russia there can be allocated 5 zones with similar NPL. Zones have received conventions A, B, B1, B2, C. Zone A includes the Murmansk region. Zone B includes the Republic of Karelia, the Republic of Komi and the Arkhangelsk Region. Zone C includes the Vologda Region. Zone B1 is allocated in the border zone of the Republic of Karelia with Finland. Zone B2 is allocated in the eastern part of the Komi Republic. For each zone, systems of harvesting machines have been identified, which make it possible to reduce the negative impact on the forest ecosystem during harvesting.
\end{abstract}

Keywords: typification of natural-production conditions, the European North of Russia, forest machine systems 
Эффективное управление лесами требует, с одной стороны, решения задачи поддержания экологической устойчивости природных систем, а с другой - задачи получения максимальной экономической эффективности от освоения биомассы древесины. Решение данного круга задач обуславливается применяемыми лесозаготовительными технологиями и типами лесозаготовительных машин. Экономическая эффективность и экологическая безопасность лесозаготовок зависит от степени адаптации используемых лесозаготовительных машин и технологий к природнопроизводственным условиям (ППУ).

ППУ варьируются даже в пределах небольших территорий. Поэтому определение ограниченного числа территорий со схожими ППУ и обоснование техники и технологии лесозаготовок, применяемых на таких территориях, является первостепенным вопросом в области сохранения лесов. В России последнее комплексное исследование в данной области выполнено в 1980-х гг. [1]. Исследования были поведены в масштабах всей страны (СССР). Основными факторами выделения зон со схожими ППУ являлись размер деревьев в древостое и рельеф. Современные исследования подтверждают необходимость учитывать размеры деревьев в древостое и рельеф при обосновании техники и технологии лесозаготовок [2, 3]. Однако также необходимо учитывать запас древесины на единицу площади, расположение эксплуатационного фонда и его доступность освоения [4-6], а также почвенно-грунтовые условия и породный состав древостоев $[7,8]$.

Цель данного исследования заключается в выделении групп лесных территорий на Европейском Севере России (ЕСР) со схожими природно-производственными условиями лесозаготовок.

В настоящее время на ЕСР широко применяются машины тяжелого класса, негативные последствия которых выражены в наибольшей степени. Это обусловлено величиной удельного давления машин на почву, соприкосновением технологического оборудования с элементами экосистемы леса, уровнем выброса газов в атмосферу и др. Для ЕСР имеются отдельные исследования, посвященные обоснованию лесозаготовительных технологий, направленных на минимизацию техногенного воздействия на лесную среду [9]. Результатами исследований такого рода являются рекомендации по использованию определенных типов лесозаготовительных машин. Однако не дается ответ на вопрос о географическом положении территорий, на которых должна применяться техника. Ввиду этого дополнительной целью исследований является разработка рекомендаций для отдельныХ территорий ЕСР по применению лесозаготовительных машин, направленных на минимизацию техногенного воздействия на лесную среду в процессе лесозаготовок.

\section{Материалы и методы исследования}

Решение поставленных задач может быть осуществлено на основе разработанной нами методики аналитической типизации ППУ лесозаготовок. Методика базируется на кластерном анализе. Задача кластерного анализа заключается в том, чтобы на основании некоторой совокупности данных $I$ разбить множество объектов $T \in T$ на т подмножеств $M_{1}, M_{2} \ldots M_{j}$, так, чтобы каждый объект $T_{i}$ принадлежал только одному подмножеству, причем объекты в подмножестве должны быть сходными. Совокупность данных $I$ представляет собой индикаторы, характеризующие природно-производственные условия множества объектов $T_{i}$. Объекты $T_{i}$ представляют собой определенные территории, где осуществляется лесозаготовка. Подмножества объектов $M_{1}, M_{2} \ldots M_{j}$ (кластеры) представляют собой группы территорий со схожими природно-производственными условиями. Попадание в один или разные кластеры объектов определяется понятием расстояния между объектами в n-мерном пространстве, где $n$ это количество выбранных индикаторов, характеризующих природно-производственные условия.

Методики включает следующие основные этапы:

1) сбор данных, характеризующих ППУ регионов;

2) определение значений индикаторов, характеризующих ППУ;

3) формирование наборов из индикаторов, по которым осуществляется сравнение регионов;

4) типизация регионов на основе кластерного анализа.

Исследования проведены для регионов ECP: Мурманской области, Республики Карелия, Архангельской области, Вологодской области, Республики Коми. Источниками данных, характеризующих ППУ регионов, являлись лесные планы субъектов Российской Федерации, данные Федерального агентства лесного хозяйства РФ, картографические материалы регионов ЕСР, находящихся в открытом доступе.

В табл. 1 приведены значения индикаторов для регионов ЕСР. 
Индикаторы, характеризующие ППУ для регионов ЕСР

\begin{tabular}{|c|c|c|c|c|c|c|}
\hline \multirow{2}{*}{$\begin{array}{c}\text { № } \\
\Pi / \Pi\end{array}$} & \multirow[t]{2}{*}{ Наименование индикатора } & \multicolumn{5}{|c|}{ Значения индикаторов } \\
\hline & & 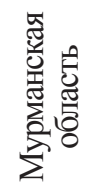 & 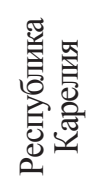 & 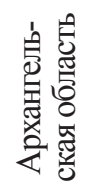 & 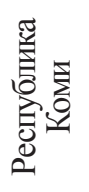 & 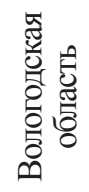 \\
\hline 1 & Средняя ступень толщины, см & 20 & 22 & 21 & 22 & 20 \\
\hline 2 & Наиболее встречающаяся ступень толщины, см & 12 & 16 & 16 & 20 & 16 \\
\hline 3 & Максимальная ступень толщины, см & 48 & 56 & 52 & 56 & 52 \\
\hline 4 & Средний объем хлыста, м³ & 0,192 & 0,205 & 0,226 & 0,24 & 0,328 \\
\hline 5 & Максимальный объем хлыста, м $^{3}$ & 0,23 & 0,351 & 0,296 & 0,4 & 0,42 \\
\hline 6 & Минимальный объем хлыста, м³ & 0,17 & 0,134 & 0,164 & 0,12 & 0,26 \\
\hline 7 & Средняя высота древостоя, м & 18 & 21 & 21 & 21 & 25 \\
\hline 8 & Средний класс бонитета & 5 & 4 & 4 & 4 & 3 \\
\hline 9 & Уклон поверхности до $15^{\circ}, \%$ & 99,9 & 100 & 100 & 99,8 & 100 \\
\hline 10 & Уклон поверхности 16-25% \% & 0,1 & 0 & 0 & 0,2 & 0 \\
\hline 11 & Уклон поверхности более $26^{\circ}, \%$ & 0 & 0 & 0 & 0 & 0 \\
\hline 12 & Грунты первой категории,\% & 16 & 8 & 3 & 4 & 1 \\
\hline 13 & Грунты второй категории,\% & 74 & 32 & 27 & 30 & 32 \\
\hline 14 & Грунты третьей категории, \% & 3 & 38 & 30 & 18 & 34 \\
\hline 15 & Грунты четвертой категории, \% & 7 & 22 & 40 & 48 & 33 \\
\hline 16 & Средний запас на га, м³ & 44 & 102 & 120 & 101 & 168 \\
\hline 17 & Минимальный запас на га, м³ & 29 & 70 & 81 & 57 & 126 \\
\hline 18 & Максимальный запас на га, м³ & 53 & 200 & 275 & 160 & 229 \\
\hline 19 & Доля сосны в древостоях,\% & 53,8 & 52,4 & 21,9 & 27,4 & 23,4 \\
\hline 20 & Доля ели в древостоях, \% & 34,7 & 35,9 & 65,1 & 66,5 & 26,8 \\
\hline 21 & Доля березы в древостоях,\% & 11,5 & 9,9 & 10 & 0,2 & 36,1 \\
\hline 22 & Доля осины в древостоях,\% & 0 & 1,7 & 2,6 & 3,8 & 12,2 \\
\hline 23 & Доля других пород в древостоях,\% & 0 & 0,1 & 0,4 & 2,1 & 1,5 \\
\hline 24 & Плотность автомобильных дорог, км/га & 0,8 & 1,84 & 1,5 & 1,27 & 3,1 \\
\hline
\end{tabular}

Таблица 2

Технические характеристики классов машин

\begin{tabular}{|c|c|c|c|}
\hline \multirow[t]{2}{*}{ Вид машины } & \multicolumn{3}{|c|}{ Технические характеристики } \\
\hline & Легкий класс (L) & Средний класс (М) & Тяжелый класс (Н) \\
\hline Харвестер & $\begin{array}{c}\text { мощность двигателя: } \\
\text { 80-120 кВт; вес: 7-14 т; } \\
\text { диаметр обрабатываемо- } \\
\text { го дерева до: } 50 \text { см }\end{array}$ & $\begin{array}{c}\text { мощность двигателя: } \\
\text { 120-160 кВт; вес: } 14-20 \text { т; } \\
\text { диаметр обрабатываемого } \\
\text { дерева до: } 60 \text { см } \\
\end{array}$ & $\begin{array}{c}\text { мощность двигателя: более } \\
160 \text { кВт; вес: более } 20 \text { т; } \\
\text { диаметр обрабатываемого } \\
\text { дерева: более } 60 \text { см }\end{array}$ \\
\hline Фрвардер & $\begin{array}{c}\text { мощность двигателя: } \\
\text { 80-120 кВт; грузоподъ- } \\
\text { емность: до } 12 \text { т }\end{array}$ & $\begin{array}{c}\text { мощность двигателя: } \\
\text { 120-160 кВт; грузоподъ- } \\
\text { емность: } 12-15 \text { т }\end{array}$ & $\begin{array}{c}\text { мощность двигателя: более } \\
160 \text { кВт; грузоподъемность: } \\
\text { более } 15 \text { т }\end{array}$ \\
\hline ВПМ & $\begin{array}{c}\text { мощность двигателя: } \\
\text { до } 120 \text { кВт; вес: до } 15 \text { т; } \\
\text { диаметр обрабатываемо- } \\
\text { го дерева: до } 40 \text { см }\end{array}$ & $\begin{array}{c}\text { мощность двигателя: } \\
\text { 120-180 кВт; вес: } 15-20 \text { т; } \\
\text { диаметр обрабатываемого } \\
\text { дерева: до } 50 \text { см }\end{array}$ & $\begin{array}{c}\text { мощность двигателя: более } \\
180 \text { кВт; вес: более } 25 \text { т; } \\
\text { диаметр обрабатываемого } \\
\text { дерева: более } 50 \text { см }\end{array}$ \\
\hline $\begin{array}{c}\text { Трелевочный } \\
\text { трактор }\end{array}$ & $\begin{array}{c}\text { мощность двигателя: } \\
\text { до } 80 \text { кВт; вес: 5-10 т; } \\
\text { объем трелюемой пачки } \\
\text { деревьев: до } 8 \text { м }\end{array}$ & $\begin{array}{c}\text { мощность двигателя: } \\
\text { 80-160 кВт; вес: } 10-15 \text { т; } \\
\text { объем трелюемой пачки } \\
\text { деревьев: } 8-14 \text { м }^{3}\end{array}$ & $\begin{array}{c}\text { мощность двигателя: более } \\
160 \text { кВт; вес: более } 15 \text { т; объ- } \\
\text { ем трелюемой пачки дере- } \\
\text { вьев: более } 14 \text { м }\end{array}$ \\
\hline Процессор & $\begin{array}{c}\text { мощность двигателя: } \\
\text { 80-120 кВт; вес: до } 15 \text { т; } \\
\text { диаметр обрабатываемо- } \\
\text { го дерева: до } 50 \text { см }\end{array}$ & $\begin{array}{c}\text { мощность двигателя: } \\
\text { 120-160 кВт; вес: 15-30 т; } \\
\text { диаметр обрабатываемого } \\
\text { дерева: до } 60 \text { см }\end{array}$ & $\begin{array}{c}\text { мощность двигателя: более } \\
160 \text { кВт; вес: более } 30 \text { т; } \\
\text { диаметр обрабатываемого } \\
\text { дерева: более } 60 \text { см }\end{array}$ \\
\hline
\end{tabular}


Bсе индикаторы сгруппированы по пяти наборам. Набор NPS включает индикаторы 1-24 и характеризует ППУ регионов ЕСР по всем индикаторам. Набор ATD включает индикаторы 4, 8, 16, 19-23 и характеризует средние таксационные показатели древостоев. Набор ТМеd включает индикаторы 1, 4, 7 и характеризует размеры средних деревьев в древостоях. Набор ТМах включает индикаторы 3, 5, 7 и характеризует размеры максимальных деревьев в древостоях. Набор CLC включает индикаторы 9-15 и характеризует почвенногранатовые условия и условия рельефа.

При кластерном анализе в качестве способа определения близости между объектами использовано Евклидово расстояние. При выделении кластеров использовался метод одиночной связи. Кластерный анализ проводился с использованием программного пакета STATISTICA на ПК.

Наиболее широко применяются две системы машин [10]. Первая система (HF) включает харвестер и форвардер. Вторая система (FSP) состоит из валочно-пакетирующей машины (ВПМ), трелевочного трактора и процессора. Для разработки рекомендаций по применению лесозаготовительных машин проведена их группировка. Выделено три основных класса машин: легкий класс (L), средний класс (M), тяжелый класс $(\mathrm{H})$. Технические характеристик классов машин приведены в табл. 2.

\section{Результаты исследования и их обсуждение}

Сравнение наборов NPS показало, что ППУ в Республике Карелия и Архангельской области наиболее близки. Евклидово расстояние составляет 3,63 (табл. 3). Наиболее различными являются ППУ Мурманской области и Вологодской области. Евклидово расстояние составляет 9,91. ППУ Республики Коми близки к условиям Архангельской области (Евклидово расстояние 4,96) и Республики Карелия (Евклидово расстояние 5.41).

Таблица 3

Матрица расстояний при сравнении наборов NPS

\begin{tabular}{|c|c|c|c|c|c|}
\hline & 1 & 2 & 3 & 4 & 5 \\
\hline 1 & 0 & 6,45 & 7,05 & 7,94 & 9,91 \\
\hline 2 & 6,45 & 0 & 3,63 & 5,41 & 6,69 \\
\hline 3 & 7,05 & 3,63 & 0 & 4,96 & 5,94 \\
\hline 4 & 7,94 & 5,41 & 4,96 & 0 & 7,76 \\
\hline 5 & 9,91 & 6,69 & 5,94 & 7,76 & 0 \\
\hline
\end{tabular}

Примечание . 1 - Мурманская область, 2 - Республика Карелия, 3 - Архангельская область, 4 - Республика Коми, 5 - Вологодская область.
Сравнение наборов ATD показало, что наиболее близки средние таксационные показатели древостоев Мурманской области и Республики Карелия. Евклидово расстояния составляет 1,98 (табл. 4). Средние таксационные данные Архангельская область больше всего близки к показателям Республики Коми. Евклидово расстояние составляет 2,08. Наиболее от всех регионов ЕСР по рассматриваемым характеристикам отличается Вологодская область.

Таблица 4

Матрица расстояний при сравнении наборов ATD

\begin{tabular}{|c|c|c|c|c|c|}
\hline & 1 & 2 & 3 & 4 & 5 \\
\hline 1 & 0 & 1,98 & 3,53 & 4,07 & 6,21 \\
\hline 2 & 1,98 & 0 & 2,57 & 3,31 & 4,90 \\
\hline 3 & 3,53 & 2,57 & 0 & 2,08 & 4,51 \\
\hline 4 & 4,07 & 3,31 & 2,08 & 0 & 4,72 \\
\hline 5 & 6,21 & 4,90 & 4,51 & 4,72 & 0 \\
\hline
\end{tabular}

При мечание . 1 - Мурманская область, 2 - Республика Карелия, 3 - Архангельская область, 4 - Республика Коми, 5 - Вологодская область.

В табл. 5 и 6 приведены результаты кластерного анализа при сравнении наборов TMed и ТМах.

Матрица расстояний при сравнении наборов TMed

\begin{tabular}{|c|c|c|c|c|c|}
\hline & 1 & 2 & 3 & 4 & 5 \\
\hline 1 & 0 & 2,35 & 1,69 & 2,50 & 3,79 \\
\hline 2 & 2,35 & 0 & 1,07 & 0,65 & 3,44 \\
\hline 3 & 1,69 & 1,07 & 0 & 1,03 & 2,69 \\
\hline 4 & 2,50 & 0,65 & 1,03 & 0 & 3,05 \\
\hline 5 & 3,79 & 3,44 & 2,69 & 3,05 & 0 \\
\hline
\end{tabular}

При мечание . 1 - Мурманская область, 2 - Республика Карелия, 3 - Архангельская область, 4 - Республика Коми, 5 - Вологодская область.

Таблица 6 Матрица расстояний при сравнении наборов ТМах

\begin{tabular}{|c|c|c|c|c|c|}
\hline & 1 & 2 & 3 & 4 & 5 \\
\hline 1 & 0 & 3,10 & 1,90 & 3,46 & 3,91 \\
\hline 2 & 3,10 & 0 & 1,39 & 0,63 & 2,19 \\
\hline 3 & 1,90 & 1,39 & 0 & 1,79 & 2,26 \\
\hline 4 & 3,46 & 0,63 & 1,79 & 0 & 2,02 \\
\hline 5 & 3,91 & 2,19 & 2,26 & 2,02 & 0 \\
\hline
\end{tabular}

Пр и м ечан и е . 1 - Мурманская область, 2 - Республика Карелия, 3 - Архангельская область, 4 - Республика Коми, 5 - Вологодская область. 
Размеры деревьев близки в трех регионах (Республика Карелия, Республика Коми и Архангельская область). Значения Евклидова расстояния находятся в диапазоне $0,6-1,07$ для наборов TMed и $0,63-1,79$ для наборов ТМах. Размеры максимальных деревьев и средних деревьев в Вологодской области и Мурманской области наиболее отличаются от максимальных и средних размеров деревьев в других регионах ЕСР. Значения Евклидова расстояния находятся в диапазоне 1,9-3,91 для Мурманской области и 2,02-3,91 для Вологодской области. Наиболее по размерам деревьев отличаются Мурманская и Вологодская области. Значение Евклидова расстояния составляет 3,91.

В табл. 7 приведены результаты сравнения набора CLC.

Матрица расстояний при сравнении наборов CLC

\begin{tabular}{|c|c|c|c|c|c|}
\hline & 1 & 2 & 3 & 4 & 5 \\
\hline 1 & 0 & 3,98 & 4,57 & 4,39 & 4,56 \\
\hline 2 & 3,98 & 0 & 1,53 & 3,88 & 1,39 \\
\hline 3 & 4,57 & 1,53 & 0 & 3,32 & 0,67 \\
\hline 4 & 4,39 & 3,88 & 3,32 & 0 & 3,52 \\
\hline 5 & 4,56 & 1,39 & 0,67 & 3,52 & 0 \\
\hline
\end{tabular}

При мечание . 1 - Мурманская область, 2 - Республика Карелия, 3 - Архангельская область, 4 - Республика Коми, 5 - Вологодская область.

По почвенно-грунтовым условиям наиболее близки Архангельская и Вологодская области. Евклидово расстояние 0,67. Условия Республики Карелия приближаются к условиям указанных регионов. Почвенно-грунтовые условия Мурманской области и Республики Коми значительно отличаются от других регионов ЕСР. Значения Евклидова расстояния для Мурманской области превышают 3,9, а для Республики Коми - 3,3.

Результаты исследований показывают, что ППУ в регионах ЕСР нельзя назвать одинаковыми. Регионы ЕСР за исключением Мурманской области схожи по условиям рельефа и почвенно-грунтовым условиям. По породному запасу древесины регионы ЕСР отличаются друг от друга, при этом сходны преобладающие породы. Наиболее значительно регионы ЕСР отличаются размерами деревьев в древостоях. Исследования показали, что регионы ЕСР по крупности деревьев в древостоях в порядке возрастания находятся в следующей последовательности: Мурманская область, Республика Карелия, Республика Коми, Архангельская область,
Вологодская область. Фактически по крупномерности деревьев в древостоях регионы ECP можно разделить на три группы. К первой группе, характеризующейся наиболее мелкими размерами деревьев, относится Мурманская область. Ко второй группе, характеризующейся средними размерами деревьев: Республика Карелия, Республика Коми, Архангельская область. К третьей группе, характеризующейся наиболее крупными деревьями в древостоях: Вологодская область.

На основании полученных результатов можно выделить три зоны ППУ для ЕСР (рисунок). Зоны получили условные обозначения: $A, B, C$.

Зона $A$ включает Мурманскую область. В зону $B$ входят Республика Карелия, Республика Коми и Архангельская область. В зону С входит Вологодская область. Анализ почвенно-грунтовых условий и индикаторов 9-15 показал, что целесообразно выделить дополнительные зоны, позволяющие учитывать нехарактерные почвенно-грунтовые условия и рельеф в зоне $B$ и получившие условные обозначения $B 1$ и $B 2$. Зона $B 1$ выделена ввиду наличия Западно-Карельской возвышенности, характеризующейся пересеченным рельефом. Зона $B 2$ выделяет территории Республики Коми, относящиеся к Северному, Приполярному и Полярному Уралу, также характеризующиеся сильно пересеченным рельефом.

Нами был проведен сопоставительный анализ технических характеристик лесозаготовительных машин и ППУ, на основе которого сделаны рекомендации по применяемым системам лесозаготовительных машин. Система HF наиболее применима в регионах ЕСР. В основном это обусловлено небольшими размерами лесосек (в среднем 10-15 га), низким уровнем развития лесных транспортных дорог, относительно небольшими размерами деревьев. Система FSP может использоваться в Вологодской области (в южной части).

М класс лесозаготовительных машин целесообразно использовать в Республике Карелия, Архангельской области и Республике Коми. В отличие от использования $\mathrm{H}$ класса это позволит минимизировать техногенные последствия лесозаготовок. Ввиду относительно небольших размеров деревьев L класс целесообразно использовать в Мурманской области.

За исключением Мурманской области в регионах ЕСР преобладают грунты 3 и 4 категории. Поэтому для минимизации по- 
следствия лесозаготовок необходимо использовать либо лесозаготовительные машины на гусеничном шасси, либо на колесном шасси с конфигурацией $6 \times 6$ или $8 \times 8$, снабженных гибкими цепями. Рекомендации по применяемым системам приведены в табл. 8.

\section{Заключение}

В результате проведенных исследований установлено, что на ЕСР может быть выделено 5 зон со схожими ППУ. ППУ в различных регионах ЕСР близки по условиям рельефа и почвенно-грунтовым усло- виям. Наиболее значительно регионы ЕСР различаются размерами деревьев в древостоях, средним объемом хлыста, запасом на гектар. Анализ показал, что в зависимости от зоны имеется возможность применения машин всех классов (легкого, среднего и тяжелого).

Результаты исследований могут быть полезными при обосновании лесозаготовительных технологий и техники для регионов ЕСР, обеспечивающих поддержание экологической устойчивости природных систем и экономической эффективности от освоения биомассы древесины.

Таблица 8

Рекомендуемые системы лесозаготовительных машин

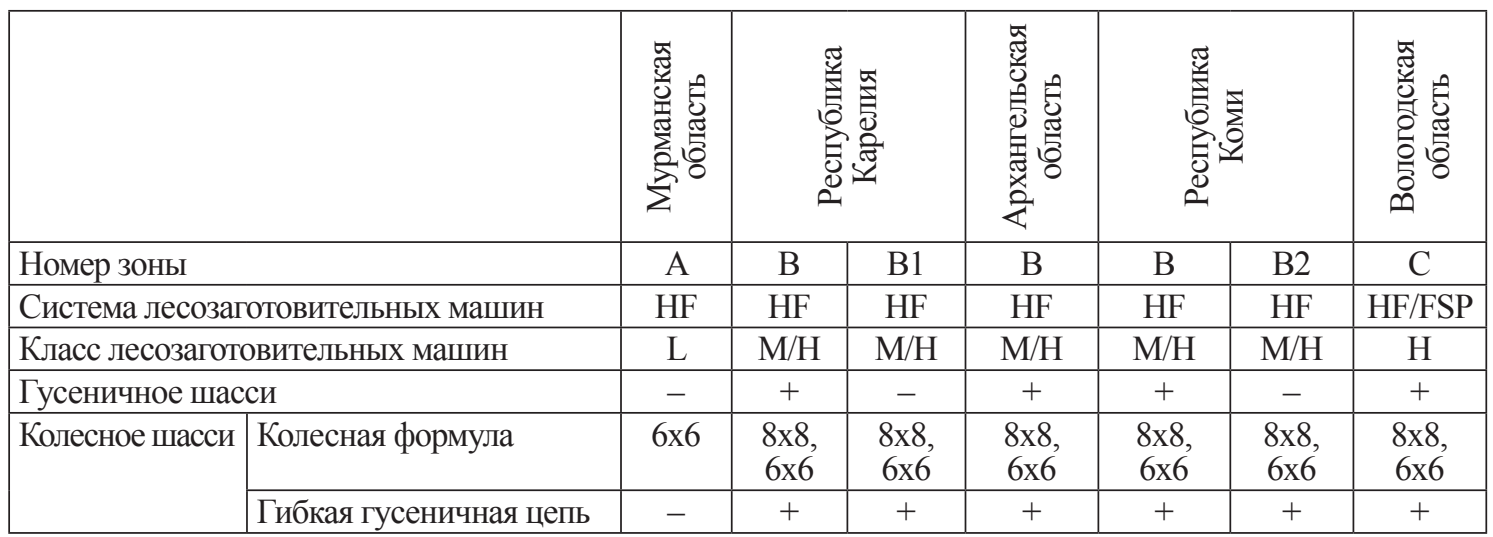

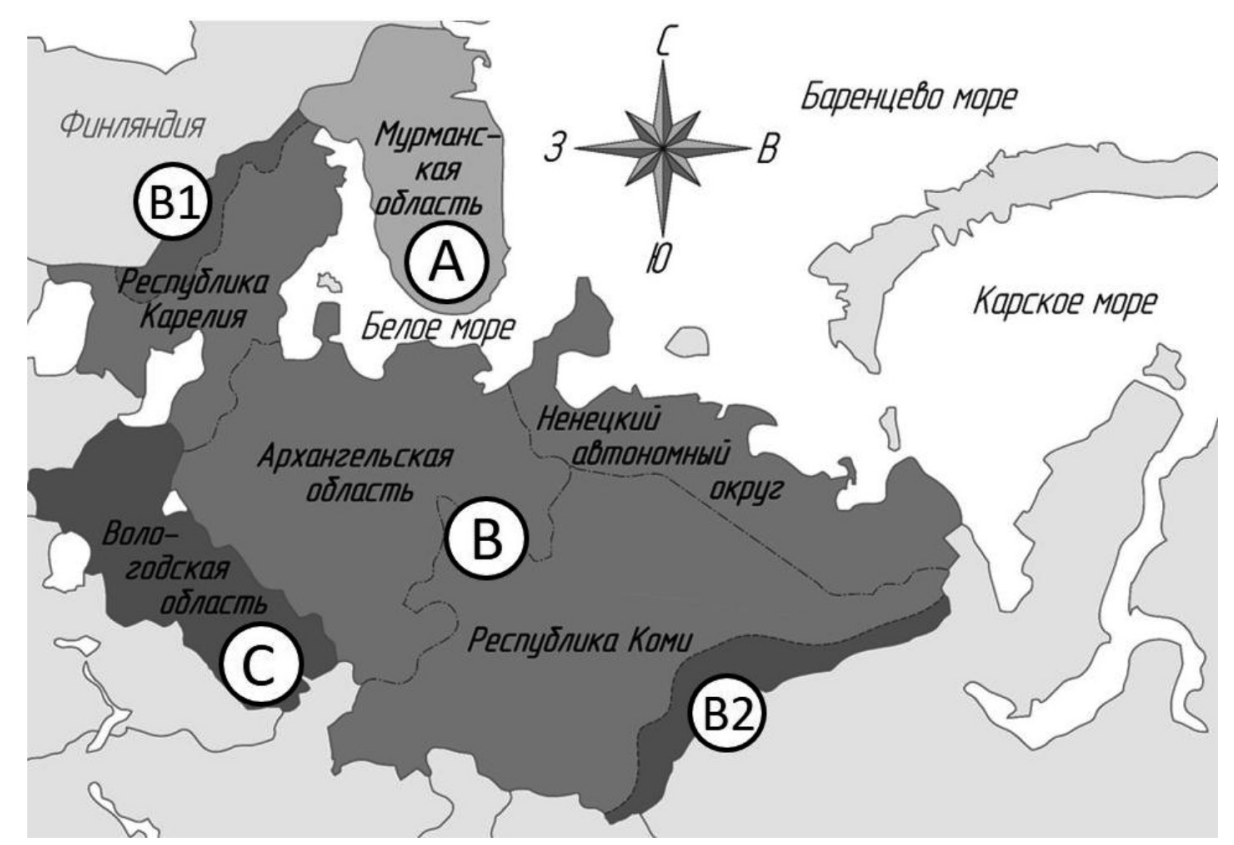

Зоньл природно-производственных условий на ЕСР 
Исследования проведены в рамках реализачии гранта Президента Российской Федерации № $M K-5321.2018 .8$.

\section{Список литературы / References}

1. Виногоров Г.К. Типизация природно-производственных условий лесозаготовительных районов. Химки: ЦНИИМЭ 1986. 23 c.

Vinogorov G.K. Typification of the natural-production conditions of logging areas. Khimki: TSNIME, 1986. 23 p. (in Russian).

2. Pierre Ackerman, Chloe Williams, Simon Ackerman, Carla Nati. Diesel Consumption and Carbon Balance in South African Pine Clear-Felling CTL Operations: a Preliminary Case Study. Croatian Journal of Forest Engineering. 2017. vol. 38. no 1. P. 65-72.

3. Castro G.P., Malinovski J.R., Nutto L., Malinovski R.A. Harvesting Systems. Tropical Forestry Handbook. Springer, Berlin, Heidelberg. 2016. P. 2445-2485.

4. Kormanek M., Baj D. Analysis of Operation Performance in the Process of Machine Wood Harvesting with Fao Fa 6840 Mini-Harvester. Agricultural engineering. 2018. vol. 22 no. 1. P. 73-82. DOI: 10.1515/agriceng-2018-0007/

5. Laitila J., Vaataine, K. The cutting productivity in integrated harvesting of pulpwood and delimbed energy wood with a forestry-equipped peat harvesting tractor. Suo. 2013. vol. 64 no 2-3. P. $97-112$
6. Pētersons J. Productivity of harvesters in commercial thinnings in the forest stands of different composition of species. Research for rural development. 2014. no 2. P. 76-82.

7. Proto A.R., Macri G., Visser R., Harrill H., Russo D., Giuseppe Zimbalatti. Factors affecting forwarder productivity. European Journal of Forest Research. 2018. vol. 137. no. 2. P. 143-151. DOI: 10.1007/s10342-017-1088-6.

8. Strandgard M., Mitchell R., Acuna M. Time consumption and productivity of a forwarder operating on a slope in a cutto-length harvest system in a Pinus radiata D. Don pine plantation. Journal of Forest Science. 2017. vol. 63. no. 7. P. 324-330. DOI: $10.17221 / 10 / 2017-J F S$.

9. Питухин А.В., Сюнев В.С. Минимизация техногенного воздействия на лесную среду в процессе лесозаготовок // Фундаментальные исследования. 2005. № 9. C. $116-120$.

Pitukhin A.V., Syunev V.S. Minimization of the technogenic impact on the forest environment in the process of logging // Fundamental research. 2005. № 9. P. 116-120 (in Russian).

10. Goltsev V., Timo Tolonen, Syunev V., Dahlin B., Gerasimov Y., Karvinen S., Leinonen T., Koponen M., Tolonen T., Jutila L., Valkky E., Vaatainen K., Seliverstrov A., Lopatin E., Monkkonen P. Wood harvesting and logistics in Russia. Working Papers of the Finnish Forest Research Institute. 2011. 210 p. URL: http://www.metla.fi/julkaisut/workingpapers/2011/ mwp210.htm (date of access: 08.17.2018). 